\title{
A questionnaire based study-assessment of knowledge, attitude and practice of pharmacovigilance among health care professionals, pre and post educational intervention
}

\author{
Husna Fatima*, Ghulam Subhani, Mohammed Mohsin, D. Nageswari Devi
}

Department of Pharmacology, Deccan College of Medical Sciences, Hyderabad, Telangana, India

Received: 26 March 2021

Revised: 29 April 2021

Accepted: 30 April 2021

*Correspondence:

Dr. Husna Fatima,

Email: fatimahusna85@gmail.com

Copyright: (c) the author(s), publisher and licensee Medip Academy. This is an open-access article distributed under the terms of the Creative Commons Attribution Non-Commercial License, which permits unrestricted non-commercial use, distribution, and reproduction in any medium, provided the original work is properly cited.

\begin{abstract}
Background: Pharmacovigilance (PV) is an important tool in generating adverse drug reaction (ADR) data. However, the practice of PV is still very low among health care professionals due to lack of knowledge and awareness. This study was conducted to assess the level of knowledge, awareness and practice of PV among health care professionals and to assess subsequent change in these after PV training session.

Methods: A cross sectional questionnaire based study was conducted among health care professionals of a tertiary health care and teaching institute. Participants were given a questionnaire. They completed it before and after undergoing training programme in PV. Impact of effectiveness of educational intervention (continuing medical education-CME (pharmacovigilance workshop) was evaluated by paired t-test.

Results: Out of 110 participants, 96 participants completely filled the questionnaire before and after the educational intervention (CME). CME on PV was found to increase knowledge and positive attitudes towards various aspects of PV.

Conclusions: Training programme on PV will help increase the knowledge as well as awareness about principles and techniques of PV and improve the rate of spontaneous ADR reporting. Organising frequent CME programmes and workshops will increase the credibility of health care in the country.
\end{abstract}

Keywords: Pharmacovigilance, Awareness, Adverse drug reactions, Knowledge, Practice

\section{INTRODUCTION}

WHO defines PV as the science which deals with detection, assessment, understanding and the prevention of adverse effects or any other drug related problems. ${ }^{1}$ Any response to a drug which is harmful and inadvertent and which occurs at normal doses used in humans for prophylaxis, diagnosis of disease, or for the moderation of physiological function is defined as ADR. ${ }^{2}$ ADRs is an alarming cause for morbidity and mortality. It accounts to about $5-20 \%$ of hospitalized patients. ${ }^{3,4}$ It causes burden both for the affected individual and also for the whole community. ${ }^{5}$ ADR monitoring and its supervision helps in decreasing the morbidity and mortality associated with it.

Under reporting is a major problem, only $6-10 \%$ of all the ADRs are reported. ${ }^{6,7}$ India has a ADR reporting rate of $1 \%$ which is much less when compared to the global ADR reporting rate of $5 \% .{ }^{8}$ To mark this problem, the ministry of health and family welfare has initiated a nationwide program known as pharmacovigilance programme of India (PvPI), which had started functioning in July $2010 .{ }^{9}$ The function of PvPI is to collect and analyse ADR data and utilize its results as a source to explain the potential risks 
related to a drug to the health care personals and also to the common population.

PvPI in collaboration with the national coordination centre, is under Indian pharmacopoeia commission. There has been progress in incidence of ADRs reporting since 2010 in India. ${ }^{10}$ Delay in detection of important ADRs is due to under reporting. Uppsala monitoring centre (UMC), the international ADR monitoring centre located at Sweden, maintains the international ADR database. It receives ADRs from all over the world. India's contribution to UMC is negligible due to absence of a vigorously active ADR monitoring system and lack of reporting culture among health care workers. ${ }^{11}$ The reporting rate of ADRs could be improved by creating awareness among all the health care professionals about importance of PV and how to fill ADR form and whom to report. Training of ADR reporting should be initiated during the undergraduate periods.

The objective behind conducting this study was to assess the awareness of PV and to assess the subsequent change in this after training session in the form of CME.

\section{METHODS}

\section{Study design and setting}

The present study is a cross sectional (KAP) questionnaire based study conducted at Deccan college of medical sciences, Hyderabad. The study participants were health care professional (staff from hospital, medical college, college of pharmacy and post-graduates). The training session which was conducted was a CMEpharmacovigilance workshop with $2 \mathrm{CME}$ credit hours awarded by Telangana state medical council. It was conducted on 30 December 2020 at Deccan college of medical sciences. The workshop was held for 8 hours (including 30 mins of pre CME-test and 30 mins of post CME-test).

\section{Design of questionnaire and data collection}

\section{Inclusion criteria}

The people who completed the questionnaire within the time limit were included in this study.

\section{Exclusion criteria}

The people who had an incomplete questionnaire were excluded from this study.

A pre-test (KAP) was conducted before CME. The questionnaire was designed by the faculty of the department of pharmacology based on the topics which were discussed during the training. After taking consent, the questionnaire was explained and was distributed among 110 participants, from which 96 completed questionnaire were considered. Questionnaire consisted of three parts. The first part (question 1-10) contained knowledge based questions. Part two (question 11-14) contained questions related to know the attitude. Part three (question 15-17) had questions to assess practical aspect of PV. All the participants were given 30 minutes to answer the questionnaire. After that, an interactive CME was conducted in the form of power point presentation by trained faculty. The CME consisted of a hands-on training and theoretical presentation on introduction to PV, its main objectives, history related to ADRs, ADRs reporting(what to report, where to report, who should report, whom to report), database, causality assessment scales, classification of ADRs, signal detection, how to fill ADR form. After CME, post CME-test (KAP) was conducted and participants were given 30 minutes time to complete the questionnaire.

\section{Statistical analysis}

Statistical analysis was done to know the impact of effectiveness of educational intervention pre and post intervention among participants. Paired t-test was used to compare the difference between total number of participants with correct responses pre and post-test. Practice of PV and ADR reporting by participants was analysed in percentage. All statistical calculations were done using R-language. The significance was assessed at $5 \%$ level of significance $(\mathrm{p}<0.05)$ with $95 \%$ confidence interval.

\section{RESULTS}

In this study out of 110 participants, only 96 returned the complete questionnaire which we have considered for our study. In pre-CME test, knowledge about the PV among the participants was assessed by part I (question 1-10) of the questionnaire (Table 1). 38 participants were aware of the definition of PV. Only 29 participants knew the full form of PvPI. Location of national coordinating centre and international centre for ADR reporting was known to only 18 and 36 participants, respectively. 12 and 42 participants could answer what is positive de-challenge and when is post marketing surveillance is done, respectively. 36 participants provided appropriate response about most commonly used scale to establish causality of an ADR, only 14 responded correctly with reference to the WHO online database for reporting ADRs. For question who can report ADR? 15 participants gave correct response, while 27 gave correct response as to which kind of ADRs should be reported. In our study, a statistically significant $(p=0.0067)$ increase in the mean values of number of participants with correct responses in knowledge part of the questionnaire was seen in the post-CME test when compared to pre-CME test. Part-II (question 11-14) of the questionnaire includes the assessment of attitude regarding PV among participants (Table 2). For the question on the 
necessity of ADR reporting, 40 participants agreed that ADR reporting should be necessary. For the question, whether ADR reporting should be mandatory, 29 participants were in favour of making it mandatory. To the question, the healthcare professional/s responsible for reporting ADRs in hospitals. 37 participants correctly answered that both healthcare and non-healthcare professionals can report. About 32 participants had positive response that PV should be taught in detail to all healthcare professionals during their curriculum. As depicted in Table 2, post-CME there was increase in number of participants who have moved towards more positive attitude regarding necessity and reporting of ADRs. Statistically significant $(\mathrm{p}=0.0026)$ was seen between pre and post mean values. Part-III included the evaluation of the practice of PV and reporting ADRs (question 15-17) of the questionnaire (Table 3 ). This study reveals that only 30 $(31.25 \%)$ participants had reported an ADR. 10 participants revealed that reason for not reporting an ADR was their unawareness about how to report. Only 60 $(62.5 \%)$ participants underwent training on reporting ADRs or PV.

Table 1: Knowledge of $\mathrm{PV}$ and $\mathrm{ADR}$ reporting before and after CME.

\begin{tabular}{|c|c|c|}
\hline \multirow[t]{2}{*}{ KAP questions } & \multicolumn{2}{|c|}{$\begin{array}{l}\text { Number of participants with correct } \\
\text { responses }\end{array}$} \\
\hline & Pre-CME $(n=96)$ & Post-CME (n=96) \\
\hline Definition of PV & 38 & 89 \\
\hline Full form of PvPI & 29 & 70 \\
\hline Where is NCC of PvPI located? & 18 & 78 \\
\hline International centre of ADR monitoring located at & 36 & 84 \\
\hline What is positive de-challenge? & 12 & 58 \\
\hline When is post marketing surveillance done? & 42 & 90 \\
\hline Which is WHO online database for ADR reporting? & 14 & 62 \\
\hline Health care professional responsible for ADR reporting in hospital & 15 & 78 \\
\hline Commonly used scale for causality establishment of ADR & 36 & 87 \\
\hline Which kind of ADRs to be reported? & 27 & 86 \\
\hline
\end{tabular}

$\mathrm{PvPI}=$ pharmacovigilance programme for India; $\mathrm{NCC}=$ national coordinating centre; $\mathrm{ADR}=$ adverse drug reaction.

Table 2: Attitude of PV and ADRs reporting before and after CME.

\begin{tabular}{|lll|}
\hline KAP questions & \multicolumn{2}{l|}{$\begin{array}{l}\text { Number of participants with correct } \\
\text { responses }\end{array}$} \\
\hline Is ADR reporting necessary? yes & Pre-CME (n=96) & Post-CME (n=96) \\
\hline Should ADR reporting made mandatory? yes & 40 & 83 \\
\hline Is teaching of PV in detail necessary? yes & 29 & 71 \\
\hline Health care professionals responsible for ADR reporting; both & 32 & 89 \\
\hline
\end{tabular}

$\mathrm{ADR}=$ adverse drug reaction; $\mathrm{PV}=$ pharmacovigilance.

Table 3: Practice of $\mathrm{PV}$ and ADR reporting before CME.

\begin{tabular}{|lll|}
\hline KAP questions & Practice & Post-CME (n=96) \\
\hline Have you ever reported any ADR? & Yes & $30(31.25)$ \\
\hline Do not know how to report & Yes & $10(10.41)$ \\
\hline Have you ever been trained on how to report ADR? & Yes & $60(62.5)$ \\
\hline
\end{tabular}

$\mathrm{ADR}=$ adverse drug reaction.

\section{DISCUSSION}

PV is an arm of patient care. So, spontaneous ADR reporting plays an important role. This study shows that there is lack of knowledge regarding PV and ADR reporting system. This may be due to limited awareness about PV. In the study, most of the participants were unaware of the correct meaning of PV. The knowledge on the location of the international centre for ADR monitoring was very poor and only few were aware about the WHO online database for reporting ADR and the most commonly used scales to establish the causality of an ADR, who can report the ADRs and what type of ADRs to report. The knowledge of PV assessed through this study is similar to the various previous studies reported in literature. ${ }^{12,13} \mathrm{~A}$ study conducted by Ramesh and Parthasarathi stated that doctors were less aware and there is lack of knowledge of national and international PV programme among doctors. ${ }^{14}$ Hema et al concluded that lack of proper knowledge and awareness about PV among the health-care professional as 
the main reason for under-reporting of ADRs. ${ }^{15}$ A study by Praveen et al concluded that the lack of knowledge and awareness was found to be the most common cause of failure in successful implementation of the PV programme of India. ${ }^{16}$ In our study, 40 participants agreed that reporting ADRs is necessary and 29 participants agreed that ADR reporting should be made mandatory. Another study found that ADR reporting was considered to be important by $97.3 \%$ of the respondents. ${ }^{17}$ In our study, the actual practice of ADR reporting was lacking. In our study we can see that there is poor practice and also insufficient knowledge regarding ADR reporting. It was found that only 30 participants had reported an ADR and the main reason for not reporting were pointed out as lack of knowledge about how to report. The above observations point out to the lack of knowledge about reporting system as one of the causes of under reporting. Similar observations were also reported in other studies. ${ }^{17-22}$ In our study, the purpose behind conducting educational intervention was to increase awareness about PV. This was demonstrated by an increase in the correct responses for each question and also increase in number of participants with correct responses post-CME test about PV and ADRs reporting with statistical significance $(\mathrm{p}=0.0067)$. A similar study was conducted among medical students in which both pre-KAP and post-KAP was conducted on PV, it showed that all the participants had very less information regarding ADRs reporting during pre-KAP studies. ${ }^{23}$ But, there was a significant improvement in their knowledge and attitude after post-KAP studies. After pre-KAP session, educational session was conducted using lectures and power point presentations as teaching tools (Bagewadi et al 2015). The use of lectures, power point presentations and diagrams increased the concept of ADRs reporting among the students. As a result, it was suggested that knowledge of PV can be increased by including PV topics in the undergraduate teaching schedule and again during internship and residency (Bagewadi et al 2015). If there is no proper ADRs reporting, a lot of ADR can occur in future. Necessary measures should be taken to implement ADR reporting practice. A recent study from India also identified that the awareness about PV program and the knowledge of ADR reporting were very low among the doctors. ${ }^{24}$ In our study, similar results were found. The outcome from study suggested the need for interventions to improve the KAP of the healthcare professionals. Workshop on PV should be conducted frequently for the students and the improvement in the responses should be assessed. A visit to the PV centre to observe the academism will help in improving the need for ADR reporting.

\section{Limitations}

The limitation of the study was that due to the COVID pandemic limited number of participants were present.

\section{CONCLUSION}

Our study suggested that there lies an insufficient knowledge and awareness about PV and its practice. The main reason for under-reporting of ADRs was found to be in adequate awareness. Enhancing the teaching programmes for medical professionals along with their routine curriculum might provide a solution to strengthen ADR reporting in India. The results of the present study suggest that an educational intervention in the form of CME/workshop/lectures can increase awareness of PV, ADRs reporting among the medical staff and the gained knowledge would thereby help them during their everyday clinical practice in future. ADR reporting should be made compulsory. Regular implementation of such a programme in health care system will increase the awareness and improve the reporting rates. This will definitely improve monitoring of medicinal use, decrease morbidity/mortality rates and hospitalization duration.

Funding: No funding sources

Conflict of interest: None declared

Ethical approval: The study was approved by the Institutional Ethics Committee

\section{REFERENCES}

1. WHO. Fact sheet: Regulation and prequalification, 2016. Available at: http://www.who.int/medicines/ areas/quality_safety/safety_efficacy/pharmvigi/en/. Accessed on 11 March 2021.

2. Adrdatabase.com. fact sheet: Adverse drug reactions database, 2016. Available at: http://www.adrdatabase. com/What\%20are\%20ADRshtml\#Definition. Accessed on 11 March 2021.

3. Lazarou J, Pomeranz BH, Corey PN. Incidence of adverse drug reactions in hospitalized patients: a metaanalysis of prospective studies. JAMA. 1998;279(15):1200-5.

4. Pirmohamed M. Adverse drug reactions as cause of admission to hospital: prospective analysis of 18,820 patients. BMJ. 2004;329(7456):15-9.

5. Ayani I, Aguirre C, Gutiérrez G, Madariaga A, Rodríguez-Sasiaín J, Martínez-Bengoechea M. A costanalysis of suspected adverse drug reactions in a hospital emergency ward. Pharmacoepidemiol Drug Safety. 1999;8(7):529-34.

6. Lopez-Gonzalez E, Herdeiro M, Figueiras A. Determinants of under-reporting of adverse drug reactions. drug safety. 2009;32(1):19-31.

7. Feely J, Moriarty S, O'Connor P. Stimulating reporting of adverse drug reactions by using a fee. BMJ. 1990;300(6716):22-3.

8. Prakash S. Pharmacovigilance in India. Indian $\mathbf{J}$ Pharmacol. 2007;39(4):123-3.

9. Gupta YK. Ensuring patient safety-launching the new pharmacovigilance programme of India. Pharma Times. 2010;42:21-6.

10. ISPOR India. Fact sheet: Pharmacovigilance programme of india (PvPI). ISPOR India, 2013. Available at: http://www.isporindia.com/wpcontent/uploads/2013/04/Dr.-V.-Kalaiselvan.pdf. Accessed on 11 March 2021. 
11. Inman WH. The attitudes to the adverse drug reaction reporting. Br J Clin Pharmacol. 1996;41(5):433-5.

12. Praveen S, Prakash RJ, Manjunath GN, Gautham MS, Kumar N. Adverse drug reaction reporting among medical and dental practitioners: a KAP study. Indian J Med Specialities. 2013;4:10-5.

13. Palaian S, Ibrahim MI, Mishra P. Health professionals knowledge, attitude and practices towards pharmacovigilance in Nepal. Pharm Pract. 2011;9(4):228-35.

14. Ramesh M, Parthasarathi G. Adverse drug reactions reporting: Attitudes and perceptions of medical practitioners. Asian J Pharm Clin Res. 2009;2(2):104.

15. Hema NG, Bhuvana KB, Sangeetha. Pharmacovigilance: the extend of awareness among the final year students, interns and postgraduates in a government teaching hospital. J Clin Diagn Res. 2012;6(7):1248-53.

16. Praveen S, Prakash RJ, Manjunath GN, Gautham MS, Kumar N. Adverse drug reaction reporting among medical and dental practitioners: A KAP study. Indian J Med Specialities. 2013;4:10-5.

17. Desai CK, Iyer G, Panchal J, Shah S, Dikshit RK. An evaluation of knowledge, attitude and practice of adverse drug reaction reporting among prescribers at a tertiary care hospital. Perspect Clin Res. 2011;2(4):129-36.

18. Gupta P, Udupa A. Adverse drug reaction reporting and pharmacovigilance: Knowledge, attitudes and perceptions among resident doctors. J Pharm Sci Res. 2011;3(2):1064-9.

19. Khan SA, Goyal C, Chandel N, Rafi M. Knowledge, attitudes and practice of doctors to adverse drug reaction reporting in a teaching hospital in India: an observational study. J Nat Sci Biol Med. 2013;4(1):191-6.

20. Hanafi S, Torkamandi H, Hayatshahi A, Gholami K, Javadi M. Knowledge, attitudes and practice of nurse regarding adverse drug reaction reporting. Iran J Nurs Midwifery Res 2012;17(1):21-5.

21. Hardeep, Bajaj JK, Kumar R. A survey on the knowledge, attitude and the practice of pharmacovigilance among the health care professionals in a teaching hospital in Northern India. J Clin Diagn Res. 2013;7(1):97-9.

22. Karelia BN, Piparava KG. Knowledge, attitude and practice of pharmacovigilance among private healthcare professionals of Rajkot city. Int J Basic Clin Pharmacol. 2014;3(1):50-3.

23. Bagewadi HG, Rekha MS, Anand SJ. A comparative evaluation of different teaching aids among fourth term medical students to improve the knowledge, attitude and perceptions about pharmacovigilance: an experimental study. Int J Pharm Res. 2015;5(4):91-7.

24. Oshikoya KA, Awobusuyi JO. Perceptions of doctors to adverse drug reaction reporting in a teaching hospital in Lagos, Nigeria. BMC Clin Pharmacol. 2009;9:14.

Cite this article as: Fatima $\mathrm{H}$, Subhani $\mathrm{G}$, Mohsin M, Devi DN. A questionnaire based studyassessment of knowledge, attitude and practice of pharmacovigilance among health care professionals, pre and post educational intervention. Int $\mathrm{J}$ Basic Clin Pharmacol 2021;10:638-42. 